Internat. J. Math. \& Math. Sci.

Vol. 22, No. 1 (1999) 147-154

S 0161-1712〈99>22147-3

(c) Electronic Publishing House

\title{
OSCILLATION OF A HIGHER ORDER NEUTRAL DIFFERENCE EQUATION WITH A FORCING TERM
}

\section{E. THANDAPANI, M. MARIA SUSAI MANUEL, JOHN R. GRAEF, and PAUL W. SPIKES}

(Received 27 May 1997 and in revised form 5 June 1997)

\begin{abstract}
The authors obtain oscillation results for the even order forced neutral difference equation

$$
\Delta^{m}\left(y_{n}+p_{n} y_{n-k}\right)+q_{n} f\left(y_{n-\ell}\right)=h_{n} .
$$

Examples illustrating the results are included.

Keywords and phrases. Difference equations, neutral, nonlinear, oscillation, asymptotic behavior.
\end{abstract}

1991 Mathematics Subject Classification. 39A10, 39A11.

1. Introduction. In this paper, we consider forced even order nonlinear neutral difference equations of the form

$$
\Delta^{m}\left(y_{n}+p_{n} y_{n-k}\right)+q_{n} f\left(y_{n-\ell}\right)=h_{n},
$$

where $m \geq 2$ is even, $k, \ell \in \mathbb{N}=\{0,1,2, \ldots\}, \Delta y_{n}=y_{n+1}-y_{n}$ is the usual forward difference operator, $\left\{p_{n}\right\},\left\{q_{n}\right\}$, and $\left\{h_{n}\right\}$ are real sequences, and $f: \mathbb{R} \rightarrow \mathbb{R}$ is continuous with $u f(u)>0$ for $u \neq 0$.

Let $\sigma=\max \{k, \ell\}$ and let $N_{0} \in \mathbb{N}$ be fixed. By a solution of (1), we mean a real sequence $\left\{y_{n}\right\}$ defined for all $n \geq N_{0}-\sigma$ and satisfying (1) for all $n \geq N_{0}$. Here, we are concerned only with the nontrivial solutions of (1). Such a solution $\left\{y_{n}\right\}$ of (1) is said to be oscillatory if, for any $N \geq N_{0}$, there exists $n>N$ such that $y_{n+1} y_{n} \leq 0$. Otherwise, the solution is said to be nonoscillatory. Throughout the paper, we assume that the following conditions hold:

(C $\left.q_{1}\right) q_{n} \geq 0$ for all $n \in \mathbb{N}$, and $q_{n}$ is not eventually identically zero;

$\left(\mathrm{C}_{2}\right) f$ is nondecreasing and there exists $K>0$ such that

$$
|f(u v)| \geq K|f(u)||f(v)| \text { for all } u, v \in \mathbb{R},
$$

and

$$
\int_{0}^{ \pm c} \frac{d s}{f(s)}<\infty \quad \text { for all } c>0 .
$$

In recent years, the oscillation of delay difference equations, especially unforced equations, has been studied by a variety of authors. For recent contributions to the literature, see, for example, the papers $[2,3,4,5,6,7,8,9,10,11]$ and the references 
contained therein. However, relatively few oscillation results are known for forced equations (see $[5,6,7,8,9,10,11]$ ). In this paper, we give sufficient conditions which ensure that all solutions of (1) are oscillatory under the influence of certain classes of forcing terms.

In the sequel, we often make use of the following conditions:

$\left(\mathrm{H}_{1}\right) \quad 0 \leq p_{n}<P_{1}<1$, where $P_{1}$ is a constant;

$\left(\mathrm{H}_{2}\right)$ there exists a real sequence $\left\{F_{n}\right\}$ such that $\Delta^{m} F_{n}=h_{n}$;

$\left(\mathrm{H}_{3}\right) \sum_{n=N_{0}}^{\infty} q_{n} f\left(\left(\frac{n-l}{2^{m-1}}\right)^{(m-1)}\right)=\infty$;

$\left(\mathrm{H}_{4}\right)\left\{F_{n}\right\}$ is oscillatory and $\lim _{n \rightarrow \infty} F_{n}=0$;

$\left(\mathrm{H}_{5}\right)\left\{F_{n}\right\}$ is $k$ periodic;

$\left(\mathrm{H}_{6}\right) \sum_{n=N_{0}}^{\infty} q_{n}=\infty$;

$\left(\mathrm{H}_{7}\right)$ there exists $\gamma>0$ such that $f(u) / u \geq \gamma>0$ for $u \neq 0$.

We also need the following lemmas whose proof can be found in [1].

LEMMA 1 ([1, Thm. 1.7.11]). Let $z_{n}>0$ be defined for $n \geq a$ with $\Delta^{m} z_{n}$ of constant sign for $n \geq a$ and not identically zero. Then there exists an integer $j, 0 \leq j \leq m$, with $m+j$ odd for $\Delta^{m} z_{n} \leq 0$ and $m+j$ even for $\Delta^{m} z_{n} \geq 0$, such that for $n \geq a$

$$
\begin{aligned}
& j \leq m-1 \text { implies }(-1)^{j+i} \Delta^{i} z_{n}>0 \quad \text { for } j \leq i \leq m-1 \\
& j \geq 1 \text { implies } \Delta^{i} z_{n}>0 \quad \text { for } 1 \leq i \leq j-1 .
\end{aligned}
$$

LEMMA 2 ([1, Cor. 1.7.12]). Let $z_{n}>0$ be defined for $n \geq a$ with $\Delta^{m} z_{n} \leq 0$ for $n \geq a$ and not eventually identically zero. Then there exists an integer $N_{1} \geq a$ such that

$$
z_{n} \geq \frac{\left(n-N_{1}\right)^{(m-1)}}{(m-1) !} \Delta^{m-1} z_{2^{m-j-1} n}
$$

for $n \geq N_{1}$, where $j$ is defined in Lemma 1 .

REMARK 1. Observe that under the hypotheses of Lemma 1 , if $z_{n}$ is increasing, then

$$
z_{n} \geq \frac{1}{(m-1) !}\left(\frac{n}{2^{m-1}}\right)^{(m-1)} \Delta^{m-1} z_{n}
$$

for $n \geq 2^{m-1} N_{1}$.

2. Main results. Our first theorem is a new result for unforced equations, but the technique of proof will be used in subsequent theorems for forced equations.

THEOREM 1. Let $h_{n} \equiv 0$ for all $n \in \mathbb{N}$, and let $\left(H_{1}\right)$ and $\left(H_{3}\right)$ hold. Then all solutions of (1) are oscillatory.

Proof. Let $\left\{y_{n}\right\}$ be a solution of (1) with $y_{n}>0, y_{n-k}>0$, and $y_{n-\ell}>0$ for $n \geq N_{1} \geq N_{0}$. Setting

$$
z_{n}=y_{n}+p_{n} y_{n-k},
$$

we obtain $z_{n} \geq y_{n}>0$ and

$$
\Delta^{m} z_{n}=-q_{n} f\left(y_{n-\ell}\right) \leq 0
$$


for $n \geq N_{1}$. By Lemma 1 , there exists an odd integer $j$ with $0 \leq j \leq m$ such that

$$
\Delta^{i} z_{n}>0 \text { for } i=1, \ldots, j-1
$$

and

$$
(-1)^{j+i} \Delta^{i} z_{n}>0 \text { for } i=j, j+1, \ldots, m-1
$$

for $n \geq N_{2}$ for some $N_{2} \geq N_{1}$.

Since $m$ is even, $\Delta z_{n}>0$ and $\Delta^{m-1} z_{n}>0$ for $n \geq N_{2}$. From (7), we have

$$
z_{n}-p_{n} y_{n-k}=y_{n}
$$

so $z_{n} \geq y_{n}$ and $\left\{z_{n}\right\}$ increasing imply that

$$
0<\left(1-P_{1}\right) z_{n} \leq\left(1-p_{n}\right) z_{n} \leq y_{n}
$$

Again, since $z_{n}$ is increasing, Remark 1 and (11) imply that there exists $N_{3} \geq N_{2}$ such that

$$
y_{n} \geq\left(1-P_{1}\right) z_{n} \geq \frac{\left(1-P_{1}\right)}{(m-1) !}\left(\frac{n}{2^{m-1}}\right)^{(m-1)} \Delta^{m-1} z_{n}
$$

for $n \geq 2^{m-1} N_{3}$. Applying $\left(C_{2}\right)$ to (12) yields

$$
\begin{aligned}
f\left(y_{n-\ell}\right) & \geq K^{2} f\left(\frac{\left(1-P_{1}\right)}{(m-1) !}\right) f\left(\left(\frac{n-\ell}{2^{m-1}}\right)^{(m-1)}\right) f\left(\Delta^{m-1} z_{n-\ell}\right) \\
& \geq K_{1} f\left(\left(\frac{n-\ell}{2^{m-1}}\right)^{(m-1)}\right) f\left(\Delta^{m-1} z_{n}\right)
\end{aligned}
$$

for $n \geq N_{4} \geq 2^{m-1} N_{3}$, where $K_{1}=K^{2} f\left(\frac{\left(1-P_{1}\right)}{(m-1) !}\right)>0$. Combining (8) and (13), we obtain

$$
\Delta^{m} z_{n}+K_{1} q_{n} f\left(\left(\frac{n-\ell}{2^{m-1}}\right)^{(m-1)}\right) f\left(\Delta^{m-1} z_{n}\right) \leq 0
$$

for $n \geq N_{4}$ and summing, we get

$$
K_{1} \sum_{s=N_{4}}^{n-1} q_{s} f\left(\left(\frac{s-\ell}{2^{m-1}}\right)^{(m-1)}\right) \leq-\sum_{s=N_{4}}^{n-1} \frac{\Delta^{m} z_{s}}{f\left(\Delta^{m-1} z_{s}\right)} \leq \int_{\Delta^{m-1} z_{n}}^{\Delta^{m-1} z_{N_{4}}} \frac{d u}{f(u)} .
$$

Letting $n \longrightarrow \infty$ and using $\left(\mathrm{C}_{2}\right)$, we get

$$
\sum_{n=N_{4}}^{\infty} q_{n} f\left(\left(\frac{n-\ell}{2^{m-1}}\right)^{(m-1)}\right)<\infty
$$

which contradicts $\left(\mathrm{H}_{3}\right)$.

THEOREM 2. If $\left(\mathrm{H}_{1}\right)$ and $\left(\mathrm{H}_{2}\right)-\left(\mathrm{H}_{4}\right)$ holds, then all the solutions of (1) are oscillatory. 
PROoF. Let $\left\{y_{n}\right\}$ be a nonoscillatory solution of (1) with $y_{n}>0, y_{n-k}>0$, and $y_{n-\ell}>0$ for all $n \geq N_{1} \geq N_{0}$. For $n \geq N_{1}$, let

$$
x_{n}=y_{n}+p_{n} y_{n-k}-F_{n} .
$$

Then from (1) and $\left(\mathrm{H}_{2}\right)$,

$$
\Delta^{m} x_{n}=-q_{n} f\left(y_{n-\ell}\right) \leq 0 .
$$

Hence, $x_{n}>0$ or $x_{n}<0$ for $n \geq N_{2}$ for some $N_{2} \geq N_{1}$. But $x_{n}<0$ implies that $0<$ $y_{n}<F_{n}$ for $n \geq N_{2}$ which is impossible since $\left\{F_{n}\right\}$ oscillates. Thus, $x_{n}>0$ for $n \geq N_{2}$. From Lemma 1, it follows that there is an odd integer $j$ with $0 \leq j \leq m$ such that

$$
\Delta^{i} x_{n}>0, \text { for } i=1, \ldots, j-1
$$

and

$$
(-1)^{j+i} \Delta^{i} x_{n}>0, \quad \text { for } i=j, j+1, \ldots, m-1
$$

for $n \geq N_{3} \geq N_{2}$.

Clearly, $\Delta x_{n}>0$ for $n \geq N_{3}$. For $0<\epsilon<\left(1-P_{1}\right) x_{N_{3}}$, $\left(\mathrm{H}_{4}\right)$ implies that there exists an integer $N_{4}>N_{3}$ such that $\left|F_{n}\right|<\epsilon / 2$ for $n \geq N_{4}$. From (17), we have $y_{n} \leq x_{n}+F_{n}$. So

$$
x_{n}-p_{n} x_{n-k} \leq y_{n}-F_{n}+p_{n} F_{n-k}<y_{n}+\frac{\epsilon}{2}+\frac{\epsilon}{2} p_{n} .
$$

Hence,

$$
0<\left(1-P_{1}\right) x_{N_{3}}-\epsilon<\left(1-P_{1}\right) x_{n}-\epsilon<y_{n}
$$

for $n \geq N_{4}$. Setting $r_{n}=\left(1-P_{1}\right) x_{n}-\epsilon$ for $n \geq N_{4}$, we get $0<r_{n}<y_{n}, \Delta r_{n}>0$, and $\Delta^{m} r_{n}=-\left(1-P_{1}\right) q_{n} f\left(y_{n-\ell}\right) \leq 0$. Now, proceeding as in the proof of Theorem 1 , we again obtain a contradiction.

We can remove the "oscillatory" part in condition $\left(\mathrm{H}_{4}\right)$ and obtain the weaker conclusion that the solutions either oscillate or converge to zero.

COROLlary 3. If $\left(H_{1}\right),\left(H_{2}\right)$, and $\left(H_{3}\right)$ hold and $\lim _{n \rightarrow \infty} F_{n}=0$, then all the solutions of (1) are either oscillatory or converge to zero.

Proof. Proceeding as in the proof of Theorem 2, we again obtain that $x_{n}>0$ or $x_{n}<0$ for $n \geq N_{2}$. If $x_{n}<0$, then $0<y_{n}<F_{n}$. So, $\left\{y_{n}\right\} \longrightarrow 0$ as $n \longrightarrow \infty$. The remainder of the proof is the same as proof of Theorem 2 .

Our next result replaces condition $\left(\mathrm{H}_{4}\right)$ with a periodicity condition on forcing term.

THEOREM 4. If $\left(\mathrm{H}_{1}\right)-\left(\mathrm{H}_{3}\right)$, and $\left(\mathrm{H}_{5}\right)$ hold, then every solution of $(1)$ is oscillatory.

Proof. Let $\left\{y_{n}\right\}$ be a nonoscillatory solution of (1) with $y_{n}>0, y_{n-k}>0$, and $y_{n-\ell}>0$ for all $n \geq N_{1} \geq N_{0}$. Defining $x_{n}$ as in (17), we have that (18) holds and so either $x_{n}>0$ or $x_{n}<0$ for $n \geq N_{2}$ for some $N_{2} \geq N_{1}$. 
We claim that $\left\{y_{n}\right\}$ is bounded. If not, then $\left\{y_{n}\right\}$ is unbounded and since $0<$ $y_{n}<x_{n}+F_{n}$ and $\left\{F_{n}\right\}$ is bounded, $\left\{x_{n}\right\}$ must be unbounded and eventually positive. Clearly, $\Delta x_{n}>0$ for large $n$ since $\Delta x_{n}<0$ implies that $\left\{x_{n}\right\}$ is bounded. From (17), we have

$$
x_{n}-p_{n} x_{n-k}=y_{n}-F_{n}-p_{n} p_{n-k} y_{n-2 k}+p_{n} F_{n-k},
$$

for $n \geq N_{3}$ for some $N_{3} \geq N_{2}$. That is,

$$
\left(1-p_{n}\right) x_{n} \leq y_{n}-\left(1-p_{n}\right) F_{n},
$$

or

$$
0<\left(1-P_{1}\right)\left(x_{n}+F_{n}\right) \leq y_{n} .
$$

Since $\left\{F_{n}\right\}$ is periodic, there exist real numbers $c_{1}$ and $c_{2}$ and two increasing sequences $\left\{n_{i}^{\prime}\right\}$ and $\left\{n_{i}^{\prime \prime}\right\} \subset \mathbb{N}$ such that $\lim _{i \rightarrow \infty} n_{i}^{\prime}=\lim _{i \rightarrow \infty} n_{i}^{\prime \prime}=\infty, F_{n_{i}^{\prime}}=c_{1}, F_{n_{i}^{\prime \prime}}=c_{2}$, and $c_{1} \leq F_{n} \leq c_{2}$ for all $n \geq N_{0}$. Hence, for $n \geq n_{i}^{\prime}, i \geq 1$, we have

$$
x_{n}+c_{1} \geq x_{n_{i}^{\prime}}+c_{1}=x_{n_{i}^{\prime}}+F_{n_{i}^{\prime}} \geq y_{n_{i}^{\prime}}>0
$$

Thus,

$$
0<\left(1-P_{1}\right)\left(x_{n}+c_{1}\right) \leq\left(1-P_{1}\right)\left(x_{n}+F_{n}\right) \leq y_{n}
$$

for $n \geq n_{i}^{\prime}$. Setting $r_{n}=\left(1-P_{1}\right)\left(x_{n}+c_{1}\right)$ for $n \geq n_{i}^{\prime}$, and $i \geq 1$, we obtain $0<r_{n} \leq y_{n}$, $\Delta r_{n}>0$, and

$$
\Delta^{m} r_{n}=-\left(1-P_{1}\right) q_{n} f\left(y_{n-\ell}\right) \leq 0
$$

Now, applying Lemma 1 and proceeding as in the proof of Theorem 1, we arrive at a contradiction. Thus, our claim holds, that is, $\left\{y_{n}\right\}$ is bounded.

The boundedness of $\left\{y_{n}\right\}$ implies that $\left\{x_{n}\right\}$ is bounded. Since $m$ is even, $j$ is odd. So (19) implies that $\Delta x_{n}>0$ for $n \geq N_{2}$. Again, proceeding as the proof of Theorem 1 , we arrive at a contradiction. Hence, $\left\{y_{n}\right\}$ is oscillatory.

REMARK 2. With appropriate modifications in condition $\left(\mathrm{C}_{1}\right),\left(\mathrm{C}_{2}\right)$, and $\left(\mathrm{H}_{3}\right)$, Theorems 1, 2, and 4 and Corollary 3 also hold for the more general equation

$$
\Delta^{m}\left(y_{n}+p_{n} y_{n-k}\right)+\sum_{j=1}^{m} q_{j, n} f_{j}\left(y_{n-\ell_{j}}\right)=h_{n} .
$$

Our final result, in this paper, is for the case $p_{n} \equiv 1$.

THEOREM 5. If $p_{n} \equiv 1$ and the conditions $\left(\mathrm{H}_{2}\right)$ and $\left(\mathrm{H}_{5}\right)-\left(\mathrm{H}_{7}\right)$ hold, then all the solutions of (1) are oscillatory.

Proof. Let $\left\{y_{n}\right\}$ be a nonoscillatory solution of (1) with $y_{n}>0, y_{n-k}>0$, and $y_{n-\ell}>0$ for all $n \geq N_{1} \geq N_{0}$. Since $\left\{F_{n}\right\}$ is periodic, there is a real number $\omega$ such 
that the sequence $\left\{F_{n}-\omega\right\}$ is oscillatory. For $n \geq N_{1}$, let $w_{n}=y_{n}+y_{n-k}-\left(F_{n}-\omega\right)$. Then

$$
\Delta^{m} w_{n}=-q_{n} f\left(y_{n-\ell}\right) \leq 0,
$$

and so $\left\{w_{n}\right\}$ is monotonic. If $w_{n}<0$ eventually, then $0<y_{n}<F_{n}-w$ for large $n$ which is impossible since $\left\{F_{n}-\omega\right\}$ oscillates. Thus, $w_{n}>0$ for $n \geq N_{2}$ for some $N_{2} \geq N_{1}$. By Lemma 1 , we have $\Delta^{m-1} w_{n}>0$ for $n \geq N_{2}$. Summing (29) from $N_{2}$ to $n-1$ and applying $\left(\mathrm{H}_{7}\right)$, we obtain

$$
\Delta^{m-1} w_{N_{2}}=\sum_{s=N_{2}}^{n-1} q_{s} f\left(y_{s-\ell}\right)+\Delta^{m-1} w_{n}>\sum_{s=N_{2}}^{n-1} q_{s} f\left(y_{s-\ell}\right)>\gamma \sum_{s=N_{2}}^{n-1} q_{s} y_{s-\ell},
$$

which yields

$$
\sum_{s=N_{2}}^{\infty} q_{s} y_{s-\ell}<\infty
$$

From Lemma 1, we see that $j$ is odd, and, hence, $\Delta w_{n}>0$ for $n \geq N_{2}$. This means that for $n \geq N_{2}$,

$$
w_{n}-w_{n-k}=y_{n}-y_{n-2 k}-\left(F_{n}-F_{n-k}\right),
$$

which, in view of $\left(\mathrm{H}_{5}\right)$, yields

$$
w_{n}-w_{n-k}=y_{n}-y_{n-2 k}>0,
$$

or $y_{n}>y_{n-2 k}$ for $n \geq N_{2}$. Therefore, $\liminf _{n \rightarrow \infty} y_{n}>0$ and so $\sum_{s=N_{2}}^{\infty} q_{s}<\infty$, which contradicts $\left(\mathrm{H}_{6}\right)$.

It should be pointed out that whether results analogous to Theorems $1,2,4$, and 5 and Corollary 3 hold when $m$ is odd remains an open question. We conclude this paper with some examples of the above theorems.

EXAMPLE 1. Consider the difference equation

$$
\Delta^{m}\left(y_{n}+\frac{1}{2} y_{n-k}\right)+3(2)^{m-1} y_{n-\ell}^{\alpha}=0,
$$

where $\alpha \in(0,1)$ is a ratio of odd positive integers, $k$ is any positive even integer, and $\ell$ is any nonnegative integer such that $\alpha \ell$ is an odd integer. It is easy to see that all the conditions of Theorem 1 are satisfied. In fact, $\left\{y_{n}\right\}=\left\{(-1)^{n}\right\}$ is an oscillatory solution of $\left(E_{1}\right)$.

EXAMPLE 2. In the equation

$$
\Delta^{m}\left(y_{n}+\frac{1}{2} y_{n-k}\right)+\left(3(2)^{m-1}-\frac{3^{m}}{2^{n+m}}\right) y_{n-\ell}^{\alpha}=\frac{(-1)^{n} 3^{m}}{2^{n+m}},
$$

let $\alpha \in(0,1)$ be the ratio of odd positive integer, $k$ an even positive integer, and $\ell$ any nonnegative integer such that $\alpha \ell$ is an odd integer. If we let $\left\{F_{n}\right\}=\left\{(-1)^{n} / 2^{n}\right\}$, then all the conditions of Theorem 2 are satisfied and, in fact, $\left\{y_{n}\right\}=\left\{(-1)^{n}\right\}$ is oscillatory solution of $\left(E_{2}\right)$. 
EXAMPLE 3. Consider the difference equation

$$
\Delta^{m}\left(y_{n}+\frac{1}{4} y_{n-k}\right)+2^{m-2} y_{n-\ell}^{\alpha}=3(2)^{m-1}(-1)^{n},
$$

where $\alpha \in(0,1)$ is a ratio of odd positive integer, $k$ is an even positive integer, and $\ell$ is any nonnegative integer such that $\alpha \ell$ is an even integer. Here, we take $\left\{F_{n}\right\}=$ $\left\{3 / 2(-1)^{n}\right\}$. Then all the conditions of Theorem 4 are satisfied and $\left\{y_{n}\right\}=\left\{(-1)^{n}\right\}$ is an oscillatory solution of $\left(E_{3}\right)$.

EXAMPLE 4. The difference equation

$$
\Delta^{m}\left(y_{n}+y_{n-k}\right)+2^{m+1} y_{n-\ell}=2^{m+2}(-1)^{n}=0,
$$

where $k$ and $\ell$ are positive even integers and $\left\{F_{n}\right\}=\left\{4(-1)^{n}\right\}$, satisfies all the conditions of Theorem 5. Here, $\left\{y_{n}\right\}=\left\{(-1)^{n}\right\}$ is an oscillatory solution of $\left(E_{4}\right)$.

ACKNOWLEDGEMENT. The research by J. R. Graef was supported by the Mississippi State University of Biological and Physical Sciences Research Institute.

\section{REFERENCES}

[1] R. P. Agarwal, Difference Equations and Inequalities, Monographs and Textbooks in Pure and Applied Mathematics, vol. 155, Marcel Dekker, Inc., New York, 1992. MR 92m:39002. Zbl 930.11533.

[2] R. P. Agarwal, M. M. S. Manuel, and E. Thandapani, Oscillatory and nonoscillatory behavior of second order neutral delay difference equations, Math. Comput. Modelling 24 (1996), no. 1, 5-11. MR 97i:39002. Zbl 856.34077.

[3] R. P. Agarwal, E. Thandapani, and P. J. Y. Wong, Oscillations of higher-order neutral difference equations, Appl. Math. Lett. 10 (1997), no. 1, 71-78. CMP 97 07. Zbl 890.39019.

[4] M. P. Chen, B. S. Lalli, and J. S. Yu, Oscillation in neutral delay difference equations with variable coefficients, Comput. Math. Appl. 29 (1995), no. 3, 5-11. MR 96f:39003. Zbl 819.39004.

[5] L. H. Erbe and B. G. Zhang, Oscillation of discrete analogues of delay equations, Differential Integral Equations 2 (1989), no. 3, 300-309. MR 90a:39001. Zbl 723.39004.

[6] J. R. Graef, J. Jaros, A. Miciano, and P. W. Spikes, Oscillation and nonoscillation results for nonlinear difference equations with a forcing term, The Proceedings of the First International Conference on Difference Equations (New York), Gordon and Breach, 1995, pp. 213-222. Zbl 860.39024.

[7] J. R. Graef, J. Jaros, A. Miciano, P. W. Spikes, and E. Thandapani, Oscillation and nonoscillation results for general nonlinear difference equations, Proceedings of Dynamic Systems and Applications (Atlanta, GA), vol. 2, Dynamic, 1996, pp. 199-206. CMP 97 04. Zbl 861.39010.

[8] B. S. Lalli and B. G. Zhang, On existence of positive solutions and bounded oscillations for neutral difference equations, J. Math. Anal. Appl. 166 (1992), no. 1, 272-287. MR 93f:39003. Zbl 763.39002.

[9] B. S. Lalli, B. G. Zhang, and J. Z. Li, On the oscillation of solutions and existence of positive solutions of neutral difference equations, J. Math. Anal. Appl. 158 (1991), no. 1, 213-233. MR 92e:39006. Zbl 732.39002.

[10] B. Szmanda, Nonoscillation, oscillation and growth of solutions of nonlinear difference equations of second order, J. Math. Anal. Appl. 109 (1985), no. 1, 22-30. MR 87e:39007. Zbl 589.39003.

[11] E. Thandapani, Oscillation theorems for perturbed nonlinear second order difference equations, Comput. Math. Appl. 28 (1994), no. 1-3, 309-316. MR 95g:39013. Zbl 807.39002. 
Thandapani: Department of Mathematics, Periyar University, Salem 636 011, TAmil NADU, INDIA

Manuel: Department of Mathematics, Sarred Heart College, Tiruppattur 635 601, INDIA

GRAEF: DePARTMENT OF MATHEMATICS AND StATISTICS, MisSisSipPi STATE UNIVERSiTy, MisSISSIPPI STATE, MS 39762, USA

SPIKES: DePARTMENT OF MATHEMATICS AND StATISTICS, MisSisSipPi STATE UNIVERSity, MisSISSIPPI STATE, MS 39762, USA 


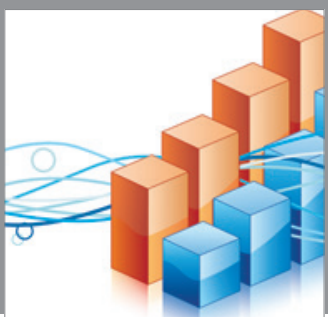

Advances in

Operations Research

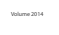

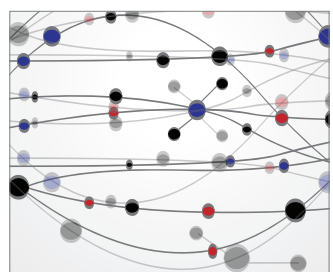

\section{The Scientific} World Journal
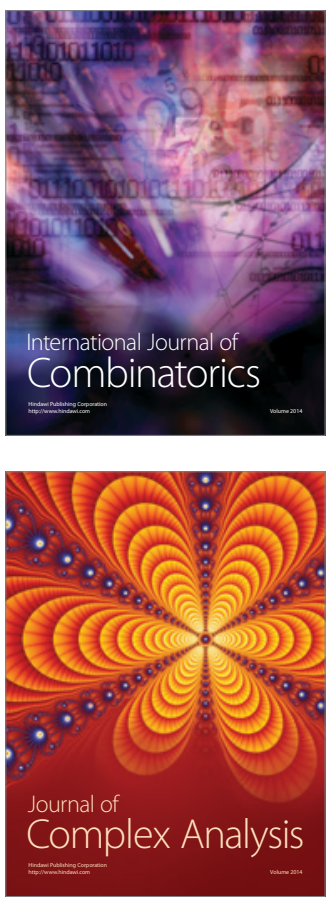

International Journal of

Mathematics and

Mathematical

Sciences
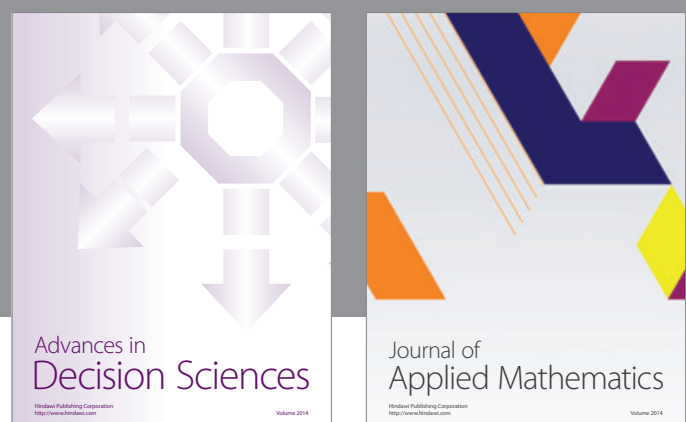

Journal of

Applied Mathematics
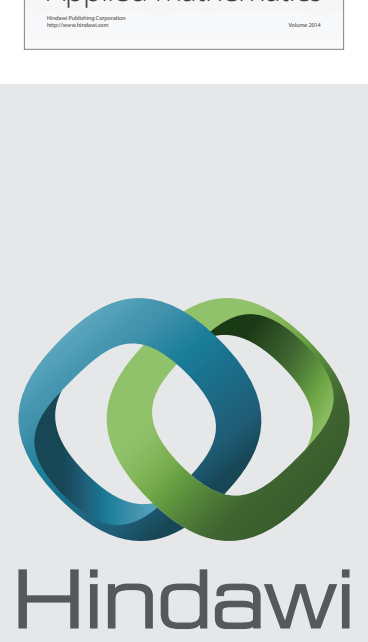

Submit your manuscripts at http://www.hindawi.com
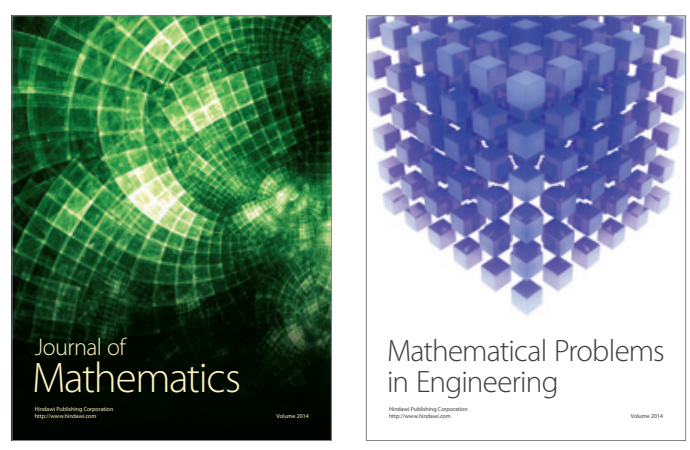

Mathematical Problems in Engineering
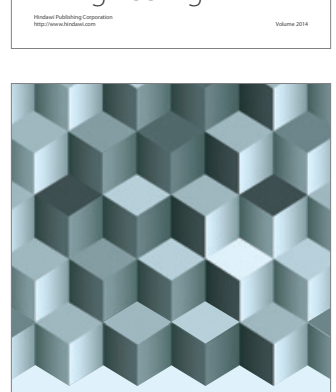

Journal of

Function Spaces
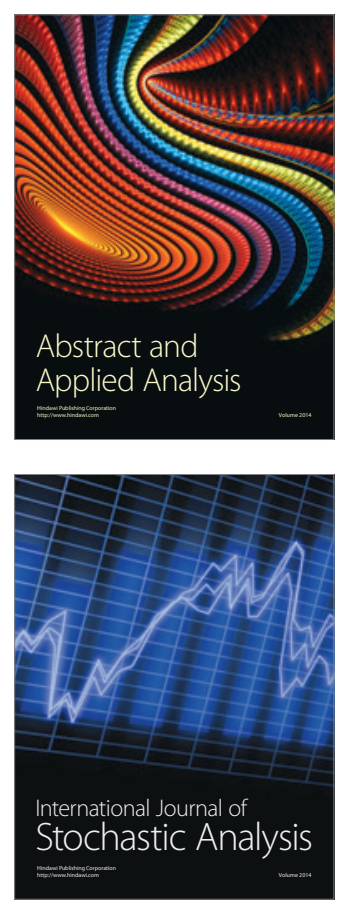

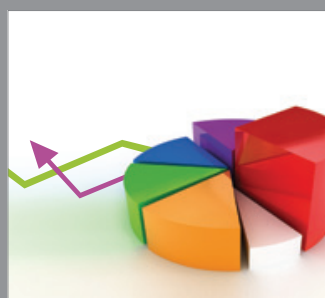

ournal of

Probability and Statistics

Promensencen
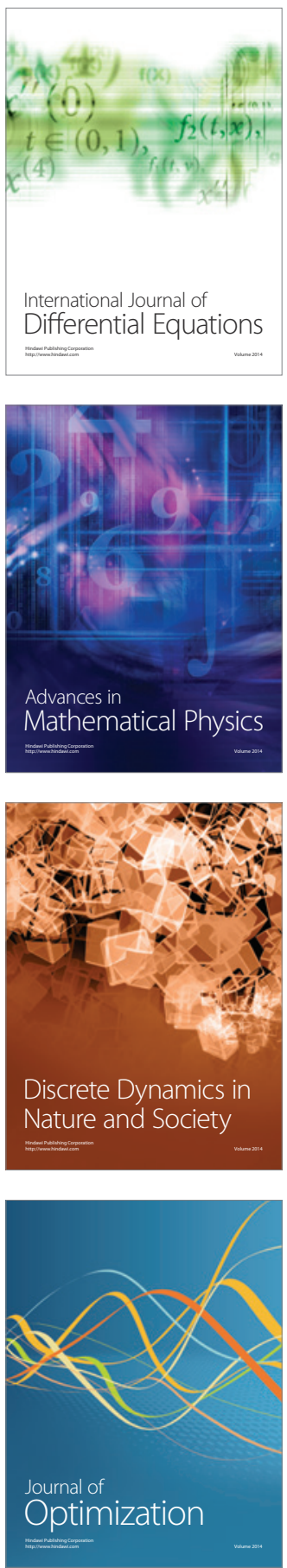